\title{
Стратегическая оценка
} эффективности диверсификации отраслевого инвестиционного портфеля

\author{
Гаврилина Д. Н. *, Огарева А. С.
}

Московская школа экономики, Московский государственный университет им. М. В. Ломоносова, Москва, Российская Федерация; dariagavrilina23@gmail.com

\begin{abstract}
PЕФЕРАТ
Инвестиционный портфель является инструментом, используемым для достижения наименьшего риска и устойчивого дохода инвестиций. При этом одной из наиболее простых и эффективных стратегий минимизации риска инвестора является диверсификация инвестиций в ценные бумаги. В статье приводятся результаты выполненного анализа эффективности диверсификации формируемого отраслевого инвестиционного портфеля на примере крупных предприятий металлургической промышленности. Выбор отрасли обусловлен тем, что металлургия является одной из наиболее динамично развивающихся отраслей мировой экономики. В исследовании был проведен анализ стратегических тенденций развития металлургической отрасли и рассмотрены три крупнейшие компании данной отрасли (ПАО «ММК», ПАО «Северсталь», ПАО «НЛМК»). Сравнительный стратегический анализ проводился по таким индикаторам финансового состояния, как коэффициенты текущей ликвидности, коэффициенты концентрации собственного капитала и финансового левериджа, а также коэффициенты обеспеченности процентов к уплате, оборачиваемость запасов и средств в расчетах, рентабельность рассматриваемых компаний.

При результирующем формировании инвестиционного портфеля были рассчитаны коэффициенты корреляции между доходностями акций этих компаний. Установлено, что финансовое положение, а также низкий коэффициент корреляции между доходностями акций исследуемых компаний позволяют сформировать отраслевой инвестиционный портфель, минимизирующий риски потенциального инвестора.
\end{abstract}

Ключевые слова: стратегия минимизации риска, стратегические тенденции, диверсификация, портфель ценных бумаг, металлургическая отрасль, финансовый анализ

Для цитирования: Гаврилина Д. Н., Огарева А. С. Стратегическая оценка эффективности диверсификации отраслевого инвестиционного портфеля // Управленческое консультирование. 2021. № 9. С. 31-44.

\section{Strategic Assessment of the Efficiency of Diversification of the Industry Investment Portfolio}

\section{Daria N. Gavrilina*, Anna S. Ogareva}

Moscow School of Economics, Lomonosov Moscow State University, Moscow, Russian Federation; dariagavrilina23@gmail.com

\section{ABSTRACT}

One of the effective special tools used to achieve the least risk and sustainable income of investment in enterprises is the investment portfolio. At the same time, one of the simplest and most effective strategies to minimize investor risk is its diversification.

The article presents the results of the performed strategic financial analysis of the effectiveness of diversification of the formed sectoral investment portfolio using the example of large enterprises of the metallurgical industry. The choice of industry was determined by the fact that metallurgy is one of the fastest growing industries in the world economy.

The article analyzes the strategic development trends of the metallurgical industry and considers the three largest companies in this industry ("MMK", "Severstal", "NLMK"). Their activity was analyzed in dynamics based on financial reporting data presented on company websites. 
Comparative analysis was carried out on such indicators of financial analysis as current liquidity ratios, equity and financial leverage concentration ratios, as well as interest-to-payment ratios, turnover of reserves and funds in turnover, profitability of the companies under consideration.

In the resulting formation of the investment portfolio, correlation coefficients between the returns of the shares of these companies were calculated. It was established that the financial situation, as well as the low correlation coefficient between the assets of the reviewed companies, allow us to form from their shares an industry investment portfolio that minimizes the risks of a potential investor.

Keywords: risk minimization strategy, strategic trends, diversification, securities portfolio, metallurgical industry, financial analysis

For citing: Gavrilina D. N., Ogareva A.S. Strategic Assessment of the Efficiency of Diversification of the Industry Investment Portfolio // Administrative consulting. 2021. N 9. P. 31-44.

\section{Введение}

С развитием экономики и фондового рынка у инвесторов появляется все больше стратегических сценариев инвестирования в финансовые активы с целью извлечения прибыли. На протяжении последних лет одним из наиболее часто применяемых методов является формирование инвестиционного портфеля, в котором представлены ценные бумаги компаний в разных пропорциях. Инвесторы при составлении такого портфеля руководствуются собственной моделью поведения и стратегией. Принципами формирования инвестиционного портфеля являются безопасность и доходность вложений, стабильный рост, высокая ликвидность ${ }^{1}$. Стратегической целью инвестора является получение прибыли в результате осуществления инвестиций в ценные бумаги, входящие в портфель, и обеспечение минимального риска финансовых операций $[1 ; 4]$. Для достижения данной цели экономистами было разработано множество различных методов.

Диверсификация - это метод, позволяющий снизить риск путем распределения инвестиций между разными финансовыми инструментами, отраслями и другими категориями активов ${ }^{2}$. Диверсификация означает распределение инвестиций среди нескольких активов вместо концентрации их всех в одном-единственном активе. Диверсификация ограничивает подверженность инвестора риску, связанному с вложением в единственный вид активов ${ }^{3}$. Многие профессионалы в области инвестиций пришли к выводу, что несмотря на то, что она не гарантирует отсутствие потерь, стратегия диверсификации является одним из наиболее важных компонентов достижения долгосрочных стратегических финансовых целей при минимизации риска.

В статье на основе произведенных расчетов было показано, что не всегда соблюдается один из принципов диверсификации, согласно которому максимальное снижение риска достигается за счет включения в портфель ценных бумаг не связанных между собой отраслей. В частности, изучена ситуация в металлургической отрасли. Выбор металлургической отрасли обусловлен ее высокой значимостью в экономике Российской Федерации. По данным Федеральной службы государ-

\footnotetext{
1 Делойт. Обзор рынка черной металлургии. Москва, второе полугодие 2019 г. [Электронный ресурс]. URL: https://www2.deloitte.com/content/dam/Deloitte/ru/Documents/research-center/ metals-2h-2019.pdf.

2 Джеймс К. Ванхорн, Джон М. Вахович. Основы финансового менеджмента. 12-е издание : пер. с англ. М. : ООО «ИД Вильямс», 2008. 1232 с.

3 Делойт. Обзор рынка черной металлургии. Москва, первое полугодие 2019 г. [Электронный pecypc]. URL: https://www2.deloitte.com/content/dam/Deloitte/ru/Documents/research-center/ metals-1h-2019.pdf.
} 
ственной статистики, в 2019 г. доля отрасли в обрабатывающей промышленности составила 19,2\% ${ }^{1}$. Также металлургия является одной из важнейших отраслей нашей страны в международном разделении труда. По производству стали Россия в настоящий момент находится на пятом месте в мире, после Китая, Индии, Японии и США [14].

\section{Материалы и методы}

Целью данной работы является стратегическая оценка эффективности диверсификации отраслевого инвестиционного портфеля на примере крупных предприятий металлургической промышленности.

Для ее достижения было предусмотрено выполнение следующих задач:

1. Провести внутренний и внешний стратегический анализ деятельности исследуемых предприятий металлургической промышленности (ПАО «ММК», ПАО «Северсталь», ПАО «НЛМК»).

2. Сформировать отраслевой инвестиционный портфель для инвестора, придерживающегося стратегии минимизации риска.

3. Оценить и сравнить эффективность диверсификации сформированных инвестиционных портфелей.

В качестве теоретической базы исследования выступают работы отечественных и зарубежных исследователей в сфере стратегии, экономики и финансового менеджмента. В работе были использованы данные научных изданий, действующего законодательства, периодической литературы, финансовой отчетности предприятий. В работе применяется описательный метод, который включает в себя наблюдение, интерпретацию и классификацию материала, использованного при изложении процесса и результатов исследования, а также приемы синтеза и анализа.

\section{Результаты}

В работе рассмотрены стратегические глобальные и национальные тенденции развития металлургии. «Результат анализа глобальных, региональных и отраслевых трендов и закономерностей затем используется для актуализации глобального прогноза, а впоследствии - для региональных и отраслевых поисковых и целеориентированных прогнозов. Так создается платформа последующих оценок возможных конкурентных преимуществ и выбора на их основе приоритетов развития» [13]. «Целеориентированные прогнозы фокусируются на трендах, которые могут привести к значительным изменениям в отраслевой структуре региона» [6].

По данным Всемирной ассоциации производителей стали (WSA), в 2018 г. в миpe (64 страны) было произведено почти 2 млрд тонн стали². Китай занимает лидирующие позиции по производству стали - 928264000 тонн, в то время как Россия заняла пятое место с производством в 72042000 тонн, годовой прирост составил 551000 тонн.

На долю азиатских стран сегодня приходится в общей сложности около 69\% выплавляемой стали. Китай активно участвует в процессах инноваций и обновления основных фондов. В стране реализуются крупные инвестиционные проекты по строительству новых и расширению существующих производственных мощностей.

\footnotetext{
1 Российский статистический ежегодник. 2019 [Электронный ресурс] / Федеральная служба государственной статистики (Росстат). М., 2019. URL: https://gks.ru/bgd/regl/b19_13/Main.htm.

2 Global crude steel output increases by $4.6 \%$ in 2018 [Электронный ресурc]. URL: https:// www.worldsteel.org/media-centre/press-releases/2019/Global-crude-steel-output-increases-by4.6--in-2018.html.
} 


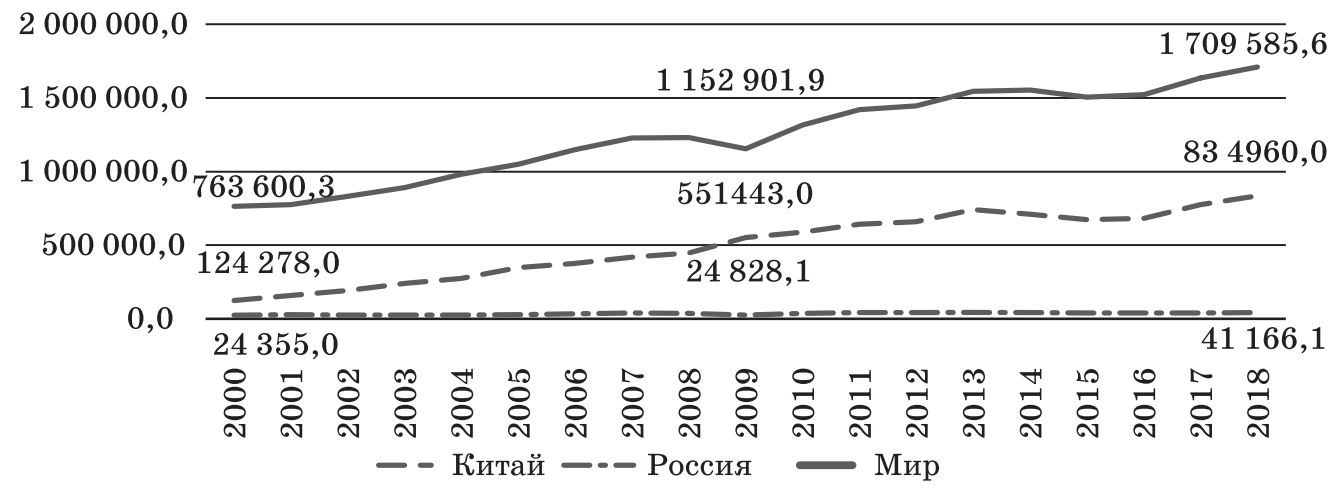

Рис. 1. Потребление стали, тыс. т

Fig. 1. Steel consumption, thousand tons

Источник: 2020 World Steel Association, Steel Statistical Yearbook 2019.

За прошедший год потребление металлопродукции в Китае увеличилось на 7,9\%, достигнув почти 735 млн тонн. Рост объемов производства стали в России был вызван, среди прочего, увеличением внутреннего спроса. В 2019 г. среднее значение роста потребления стали в мире составило 4,6\% по сравнению с 2018 г. (рис. 1).

В черной металлургии можно выделить следующие стратегические глобальные тенденции: рост производительности труда и операционной эффективности; рост доли инновационной продукции; рост экологических инноваций (повышение внимания к экологичности производства) [2]. В 2019 г. крупнейшими производителями стали в РФ были представлены обновленные стратегии развития до 2023 г., которые предполагают увеличение капитальных расходов на расширение и модернизацию производственных мощностей. Планируется, что с 2021 г. эти инвестиции приведут к возобновлению роста производства стали в России 1 .

В качестве стратегических глобальных тенденций в области цветной металлургии можно выделить: рост потребления продукции цветной металлургии; ужесточение требований по экологичности производства; рост заинтересованности предприятий в развитии производств более высоких переделов: компании, лидирующие на мировом рынке первичного алюминия, не первый год диверсифицируют бизнес за счет расширения производства различной металлической продукции, эта тенденция поддержит темпы роста мирового спроса и цены на цветные металлы [12].

Ключевыми национальными тенденциями развития отечественной металлургии, которые были определены в стратегиях развития металлургического производства, являются ${ }^{2}:$ замедление темпов роста объемов производства и потребления металлопродукции; увеличение доли продукции, поставляемой на внутренний рынок; увеличение поставок на экспорт продукции с увеличением глубины переработки; рост импортозамещения; повышение требований к служебным характеристикам продукции, совершенствование ее сортамента и конкурентоспособности; ресурсои энергосбережение, снижение негативного экологического воздействия на окру-

1 Делойт. Обзор рынка черной металлургии. Москва, 2020 г. [Электронный ресурc]. URL: https://www2.deloitte.com/ru/ru/pages/research-center/articles/overview-of-steel-and-ironmarket-2020.html.

2 Стратегии развития черной и цветной металлургии России на 2014-2020 гг. и на перспективу до 2030 г. 
жающую среду; оптимизация избыточных производственных мощностей; строительство мини-заводов, передельных и сервисных центров; внедрение новой техники и технологий.

Компании «ММК», «Северсталь», «НЛМК», «ЕВРАЗ», «Металлоинвест» и «Мечел» в первом полугодии 2019 г. всего произвели 31700000 тонн стали (87\% производства стали в РФ) ${ }^{1}$. Проведенный стратегический финансовый анализ некоторых из этих компаний, а именно, ПАО «ММК», ПАО «Северсталь», ПАО «НЛМК» (табл. 1), был обусловлен тем, что данные предприятия входят в список крупнейших производителей по рейтингу Мировой ассоциации стали [14].

По производительности, выручке и EBITDA первое место занимает ПАО «НЛМК». В ПАО «Северсталь» наибольший показатель чистой прибыли и EBITDA. Расчет EBITDA используется для измерения операционной рентабельности компании, поскольку он учитывает только те расходы, которые необходимы для «ежедневного» ведения бизнеса [10; 11]. Перейдем к расчету коэффициентов стратегического финансового анализа и более детальному сравнению компаний. Первая группа индикаторов финансового состояния - показатели ликвидности (табл. 2), которые являются внешними характеристиками финансовой устойчивости с точки зрения степени обеспеченности оборотных активов долгосрочными источниками финансирования [4; 5].

Таблица 1

\section{Сравнительная таблица крупнейших предприятий металлургической промышленности РФ на 2019 г.}

Table 1. Comparative table of the largest enterprises of the metallurgical industry of the Russian Federation in 2019

\begin{tabular}{|l|c|c|c|}
\hline \multicolumn{1}{|c|}{ Показатель } & ПАО «ММК» & $\begin{array}{c}\text { ПАО } \\
\text { «Северсталь» }\end{array}$ & $\begin{array}{c}\text { ПАО } \\
\text { «НЛМК» }\end{array}$ \\
\hline Объем производства стали, млн тонн & 12,5 & 11,8 & 15,7 \\
\hline Выручка, млн долл. & 7566 & 8157 & 10554 \\
\hline Чистая прибыль, млн долл. & 850 & 1766 & 1341 \\
\hline Дивидендная политика, доход, \% & 15,51 & 14,27 & 17,89 \\
\hline ЕВІТDА, млн долл. & 1797 & 2805 & 2564 \\
\hline
\end{tabular}

И с точн ик: расчеты авторов, основанные на финансовой отчетности ПАО «MMK» (URL: http:// www.mmk.ru/), ПАО «Северсталь» (URL: https://www.severstal.com), ПАО «HЛMK» (URL: https:// nlmk.com/ru/).

Таблица 2

\section{Коэффициенты текущей ликвидности}

Table 2. Current ratio

\begin{tabular}{|l|c|c|c|}
\hline \multicolumn{1}{|c|}{ Компания } & $\mathbf{2 0 1 7}$ & $\mathbf{2 0 1 8}$ & $\mathbf{2 0 1 9}$ \\
\hline ПАО «ММК» & 1,840 & 1,954 & 1,911 \\
\hline ПАО «Северсталь» & 1,768 & 1,845 & 1,951 \\
\hline ПАО «НЛМК» & 2,357 & 2,098 & 1,903 \\
\hline
\end{tabular}

Источн ик: расчеты авторов, основанные на финансовой отчетности ПАО «ММК», ПАО «Северсталь, ПАО «НЛМК».

1 Делойт. Обзор рынка черной металлургии. Москва, второе полугодие 2019 г. [Электронный pecypc]. URL: https://www2.deloitte.com/content/dam/Deloitte/ru/Documents/research-center/ metals-2h-2019.pdf. 
Среднеотраслевое значение коэффициента текущей ликвидности находится в пределах от 1,5 до $2^{1}$. На основе приведенных расчетов можно сделать вывод о высокой платежеспособности рассматриваемых предприятий.

В конце 2017 г. общий объем стали, выплавленной на ММК, впервые превысил отметку в 800 млн тонн. Данный показатель является рекордным для металлургической отрасли России ${ }^{2}$. После чего в 2018 г. текущая ликвидность ПАО «ММК» резко возросла. Далее наблюдалось незначительное снижение коэффициента, это связано с увеличением краткосрочных обязательств.

На протяжении рассматриваемого периода наблюдалась тенденция роста платежеспособности у ПАО «Северсталь» (коэффициент текущей ликвидности составил 1,951 в 2019 г. за счет роста оборотных активов). Данная тенденция была вызвана увеличением на 15\% поставок российским машиностроителям и, кроме того, ростом продаж проката с покрытиями на $13 \%$ и увеличением поставок автопроизводителям на 21\%. Важным стратегическим событием 2019 г. стало снижение расхода большинства энергоресурсов на тонну продукции Череповецким металлургическим комбинатом по сравнению с прошлым годом. Экономический эффект составил 156 млн рублей ${ }^{3}$.

В ПАО «НЛМК» наблюдается снижение коэффициента за счет уменьшения денежных средств и их эквивалентов. Ключевыми моментами этого стали некоторые стратегические факторы, в том числе падение объема продаж на экспортных рынках (на 15\% до 5,8 млн тонн) из-за уменьшения поставок сортовой заготовки, а также на фоне капитальных ремонтов НЛМК. Производство стали снизилось на $10 \%$ до 15,7 млн тонн в связи с проведением капитальных ремонтов доменного и сталеплавильного производств НЛМК 4 .

Следует отметить, что коэффициенты быстрой и абсолютной ликвидности находятся в пределах среднего значения по отрасли. Далее перейдем к оценке показателей финансовой устойчивости исследуемых компаний (табл. 3).

Оптимальное отраслевое значение коэффициента концентрации собственного капитала находится в пределах от 0,5 до 0,6. Как видно из табл. 3, наблюдается тенденция снижения данного коэффициента у всех рассматриваемых предприятий. В динамике мы видим, что в 2018 г. по сравнению с 2017 г. у ПАО «ММК» и ПАО «Северсталь» наблюдался незначительный рост, а далее в 2019 г. снижение. Компании увеличивали как долю краткосрочных, так и долю долгосрочных обязательств. Такие небольшие изменения процента заемного капитала говорят о том, что за-

Таблица 3

\section{Коэффициент концентрации собственного капитала}

Table 3. Concentration of equity

\begin{tabular}{|l|c|c|c|}
\hline \multicolumn{1}{|c|}{ Компания } & $\mathbf{2 0 1 7}$ & $\mathbf{2 0 1 8}$ & $\mathbf{2 0 1 9}$ \\
\hline ПАО «ММК» & 0,692 & 0,695 & 0,666 \\
\hline ПАО «Северсталь» & 0,471 & 0,490 & 0,423 \\
\hline ПАО «НЛМК» & 0,604 & 0,587 & 0,567 \\
\hline
\end{tabular}

Источни к: расчеты авторов, основанные на финансовой отчетности ПАО «MMK», ПАО «Северсталь, ПАО «НЛМК».

\footnotetext{
1 Данные https://ru.investing.com/.

2 ПАО «ММК»[Электронный ресурc]. URL: http://www.mmk.ru/press_center/publications/.

3 ПАО «Северсталь» [Электронный ресурс]. URL: https://www.severstal.com/rus/media/news/.

4 ПАО «НЛМК»[Электронный ресурс]. URL: https://nlmk.com/ru/media-center/news-groups/.
} 
емный капитал и доля собственных средств изменяются равномерно. И такие компании значительно привлекательнее при выборе вложения инвестиций. В то время как в ПАО «НЛМК» наблюдалась тенденция снижения коэффициента за счет увеличения долгового финансирования на протяжении рассматриваемого периода.

С учетом проведенных расчетов рекомендацией для компании ПАО «ММК» по использованию капитала является формирование корпоративного венчурного фонда, что согласуется с глобальной и национальной стратегической тенденцией об увеличении стратегической значимости формирования корпоративных венчурных фондов. Данная инициатива будет способствовать росту технологичности компании путем реализации инновационных стартапов через созданный корпоративный венчурный фонд и повышению конкурентоспособности предприятия на глобальном рыночном пространстве.

Среднеотраслевое значение коэффициента финансового левериджа находится в пределах от 26 до 35\% ${ }^{1}$. Во всех рассматриваемых компаниях (табл. 4) данный показатель на протяжении рассматриваемого периода рос, но не превышал «1», т.е. активы компании финансировались в большей степени за счет собственного капитала.

По отрасли среди всех рассматриваемых компаний в 2019 г. наблюдалась тенденция снижения коэффициентов обеспеченности процентов к уплате по сравнению с 2018 г. (табл. 5). Данная тенденция была вызвана нестабильностью цен на рынке; особенно сильное колебание наблюдалось в 2019 г., когда произошла крупная авария на шахте компании Vale в Бразилии, что спровоцировало резкий скачок цен на железную руду. Возникли серьезные опасения по поводу дефицита этого сырья в мире (рис. 2). Железная руда дорожала очень быстро - с 76,03 долл. за 1 тонну в январе до 120,02 долл. за 1 тонну - в июле. К ноябрю цена резко упала - до 84,68 долл. за 1 тонну.

Таблица 4

Финансовый леверидж

Table 4. Coefficient of financial leverage

\begin{tabular}{|l|c|c|c|}
\hline \multicolumn{1}{|c|}{ Компания } & $\mathbf{2 0 1 7}$ & $\mathbf{2 0 1 8}$ & $\mathbf{2 0 1 9}$ \\
\hline ПАО «ММК» & 0,157 & 0,159 & 0,217 \\
\hline ПАО «Северсталь» & 0,630 & 0,650 & 0,908 \\
\hline ПАО «НЛМК» & 0,354 & 0,349 & 0,436 \\
\hline
\end{tabular}

Источник: расчеты авторов, основанные на финансовой отчетности ПАО «ММК», ПАО «Северсталь, ПАО «НЛМК».

Таблица 5

Обеспеченность процентов к уплате

Table 5. The interest coverage ratio

\begin{tabular}{|l|c|c|c|}
\hline \multicolumn{1}{|c|}{ Компания } & $\mathbf{2 0 1 7}$ & $\mathbf{2 0 1 8}$ & $\mathbf{2 0 1 9}$ \\
\hline ПАО «ММК» & 26,944 & 38,188 & 20,548 \\
\hline ПАО «Северсталь» & 10,444 & 21,315 & 16,387 \\
\hline ПАО «НЛМК» & 23,654 & 37,526 & 17,789 \\
\hline
\end{tabular}

Источник: расчеты авторов, основанные на финансовой отчетности ПАО «ММК», ПАО «Северсталь, ПАО «НЛМК».

\footnotetext{
1 Данные https://ru.investing.com/
} 


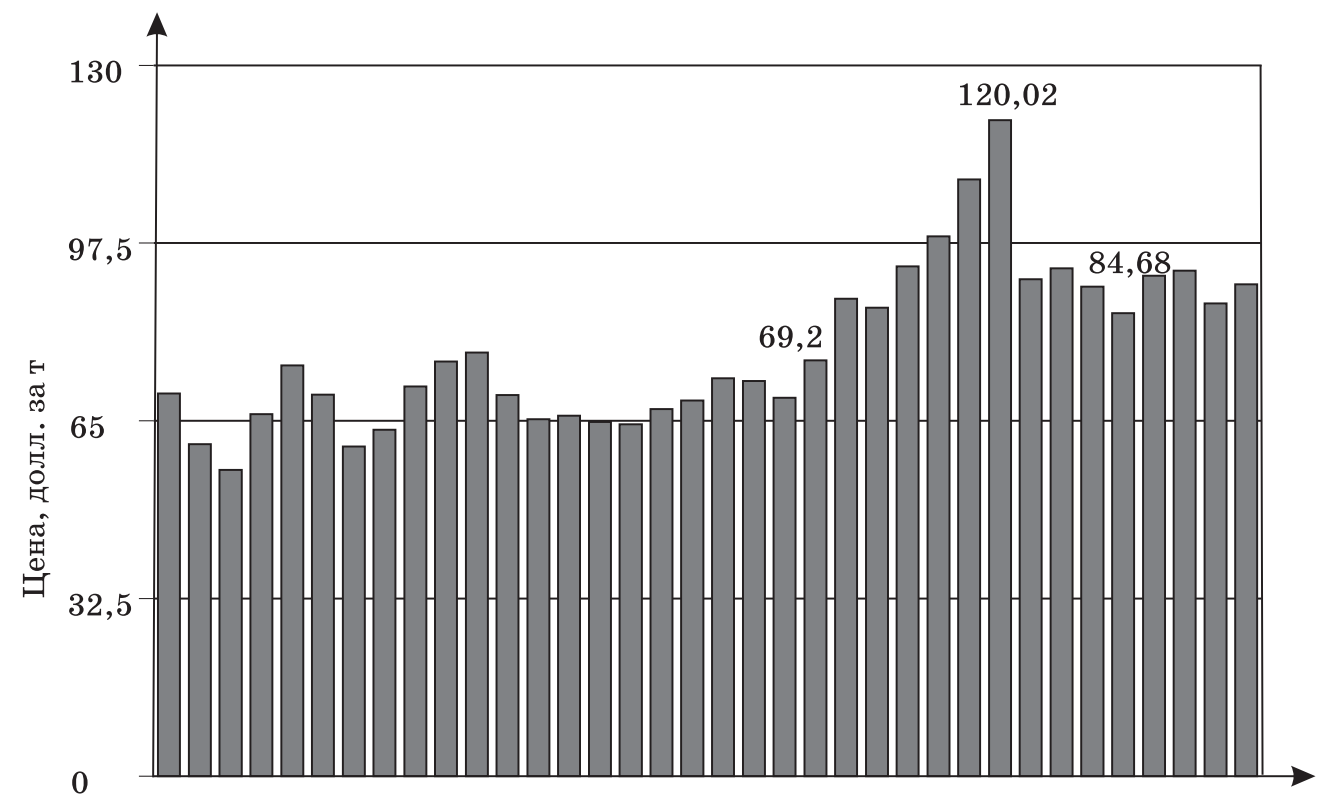

Июнь Сент. Дек. Март Июнь Сент. Дек. Март Июнь Сент. Дек. Март

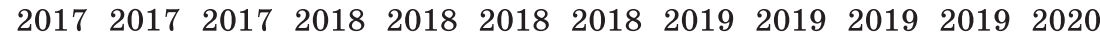
месяц год

Рис. 2. Цены на железную руду, долл. за 1 т

Fig. 2. The prices of iron ore, dollars for 1 ton

Источник: составлено авторами по статистике https://ru.investing.com/

Далее рассмотрим показатели внутрифирменной эффективности исследуемых компаний.

Оборачиваемость запасов в среднем по отрасли составляет от 3 до 4,5 оборотов ${ }^{1}$. В ПАО «ММК» коэффициент увеличился за счет снижения товарно-материальных запасов (табл. 6), в ПАО «Северсталь» происходило увеличение запасов и, как следствие, наблюдалось падение данного коэффициента. В ПАО «НЛМК» оборачиваемость запасов в оборотах сильно отличается от среднеотраслевых,

Таблица 6

Оборачиваемость запасов в оборотах / в днях

Table 6. Asset turnover ratio (times / in days)

\begin{tabular}{|l|c|c|c|}
\hline \multicolumn{1}{|c|}{ Компания } & $\mathbf{2 0 1 7}$ & $\mathbf{2 0 1 8}$ & $\mathbf{2 0 1 9}$ \\
\hline ПАО «ММК» & $4,235 / 86,192$ & $4,193 / 87,043$ & $4,531 / 80,556$ \\
\hline ПАО «Северсталь» & $4,919 / 74,195$ & $4,586 / 79,598$ & $4,414 / 82,698$ \\
\hline ПАО «НЛМК» & $1,075 / 339,636$ & $1,038 / 351,584$ & $0,964 / 378,608$ \\
\hline
\end{tabular}

Источн ик: расчеты авторов, основанные на финансовой отчетности ПАО «ММК», ПАО «Северсталь, ПАО «НЛМК».

1 Данные https://ru.investing.com/. 
а именно - оборачиваемость запасов равна 1 (в оборотах) и 340-380 (в днях). Это говорит о том, что у данной компании негативные тенденции по этим показателям. Низкая оборачиваемость запасов является плохим показателем финансовохозяйственной деятельности предприятия, в данной компании такая ситуация вызвана низкой себестоимостью продаж.

Оборачиваемость средств у ПАО «ММК» и ПАО «Северсталь» (табл. 7) сохраняется примерно на одном уровне на протяжении рассматриваемого периода и находится в пределах нормы по отрасли (в оборотах 11-15, в днях 25-30). Напротив, в ПАО «НЛМК» коэффициенты отличаются от среднеотраслевых, а именно - 2 (в оборотах) и 140-180 (в днях). Это вызвано низкими значениями выручки компании.

Далее проведем оценку показателей рентабельности рассматриваемых предприятий (табл. 8). Среднеотраслевое значение рентабельности находится в интервале от 24 до $39 \%$ [3].

Согласно среднестатистическим данным, рентабельность собственного капитала ROE находится в пределах от 10 до 12\% в США и Великобритании. Для инфляционной экономики, такой как российская, коэффициент должен быть больше.

В 2018 г. цены на сырьевые товары достигли своих пиковых значений за последние несколько лет. На это повлиял ряд стратегических факторов, в том числе - торговые споры, сокращение сталелитейных мощностей в Китае, а также различные природные катаклизмы, происходившие в течение года. В 2019 г. ра-

Таблица 7

Оборачиваемость средств в оборотах / в днях

Table 7. Inventory turnover ratio (times / in days)

\begin{tabular}{|l|c|c|c|}
\hline \multicolumn{1}{|c|}{ Компания } & $\mathbf{2 0 1 7}$ & $\mathbf{2 0 1 8}$ & $\mathbf{2 0 1 9}$ \\
\hline ПАО «ММК» & $11,263 / 32,408$ & $11,108 / 32,861$ & $11,721 / 31,140$ \\
\hline ПАО «Северсталь» & $14,493 / 25,184$ & $14,896 / 24,503$ & $14,361 / 25,416$ \\
\hline ПАО «НЛМК» & $2,579 / 141,527$ & $2,359 / 154,698$ & $1,949 / 187,315$ \\
\hline
\end{tabular}

И с точник: расчеты авторов, основанные на финансовой отчетности ПАО «MMК», ПАО «Северсталь, ПАО «НЛМК».

Таблица 8

Рентабельность, \%

Table 8. Profitability indicators, \%

\begin{tabular}{|l|l|c|c|c|}
\hline Компания & \multicolumn{1}{|c|}{ Рентабельность } & $\mathbf{2 0 1 7}$ & $\mathbf{2 0 1 8}$ & $\mathbf{2 0 1 9}$ \\
\hline \multirow{2}{*}{$\begin{array}{l}\text { ПАО } \\
\text { «MК» }\end{array}$} & собственного капитала (ROE) & 21,60 & 26,30 & 15,50 \\
\cline { 2 - 5 } & активов (ROA) & 14,60 & 18,10 & 10,20 \\
\cline { 2 - 5 } & инвестированного капитала (ROI) & 17,80 & 21,90 & 11,80 \\
\hline \multirow{2}{*}{$\begin{array}{l}\text { «АО } \\
\text { север- }\end{array}$} & собственного капитала (ROE) & 39,90 & 71,20 & 50,80 \\
\cline { 2 - 5 } & активов (ROA) & 16,90 & 33,10 & 21,60 \\
\cline { 2 - 5 } & инвестированного капитала (ROI) & 22,00 & 41,00 & 24,90 \\
\hline \multirow{2}{*}{\begin{tabular}{l} 
«АО \\
\multirow{2}{*}{ НЛМК» }
\end{tabular}} & собственного капитала (ROE) & 21,82 & 38,36 & 22,55 \\
\cline { 2 - 5 } & активов (ROA) & 13,30 & 22,62 & 12,88 \\
\cline { 2 - 5 } & инвестированного капитала (ROI) & 16,25 & 28,57 & 15,80 \\
\hline
\end{tabular}

Источник: расчеты авторов, основанные на финансовой отчетности ПАО «ММК», ПАО «Северсталь, ПАО «НЛМК». 
стущие процентные ставки, кредитные ограничения в Китае и циклическое замедление автомобильного сектора на развитых рынках оказывали негативное влияние на мировой спрос на сталь. В 2019 г. потребление стали росло медленнее ${ }^{1}$.

Среди рассматриваемых предприятий в ПАО «Северсталь» рентабельность значительно выше и составляет 50\% в 2019 г. Такое значение достигается за счет большой чистой прибыли компании. Также важно отметить явную тенденцию снижения коэффициента у всех компаний за последний год, что вызвано снижением прибыли в связи с сезонным замедлением деловой активности и снижением цен на мировых рынках стали.

Рентабельность активов прежде всего зависит от отрасли. Средний показатель по исследуемой отрасли составляет от 10 до 20\%. Наибольший коэффициент рентабельности активов у ПАО «Северсталь» $(21,6 \%)$. На данный показатель наибольшее влияние оказали два стратегических фактора: чистая прибыть и активы компании. У ПАО «Северсталь» активы компании значительно выросли в 2019 г. по сравнению с 2018 г. (на 28,6\%), в то время как чистая прибыль упала на 13\%. Противоположная ситуация у ПАО «ММК» и ПАО «НЛМК», где снижение показателей в 2019 г. по сравнению с 2018 г. вызвано в большей степени резким снижением чистой прибыли и одновременно невысоким ростом активов компаний.

Средний показатель рентабельности инвестированного капитала по отрасли составляет от 15 до 30\%. Во всех рассматриваемых компаниях данный коэффициент снизился в 2019 г. по сравнению с 2018 г. за счет увеличения долгосрочных обязательств и снижения прибыли.

Последующая часть нашего исследования состояла в том, чтобы сформировать отраслевой инвестиционной портфель. При вложении денег в ценные бумаги инвестор ставит две важные цели стратегического характера: максимизация ожидаемой доходности и минимизация риска. В зависимости от выбранной стратегии инвестор формирует оптимальный для себя портфель [7; 8]. Выборка в нашей работе составила 3000 ежедневных наблюдений цен на акции по всем рассматриваемым компаниям, а также по индексу Мосбиржи - основному индексу цен на акции наиболее ликвидных компаний на фондовой бирже. Данные были взяты с официального сайта Московской биржи (http://moex.com/). В табл. 9 представлены основные результаты расчетов по компаниям.

По результатам расчетов мы получили, что у компании ПАО «НЛМК» худшее рыночное положение относительно двух других компаний, так как акции характеризуются высоким стандартным отклонением и бета-коэффициентом, то есть высоким уровнем риска при таком же уровне ожидаемой доходности, что и у остальных предприятий. Подтвердился вывод, сделанный в фундаментальном анализе финансовой отчетности, о наименьшей привлекательности НЛМК.

Однако ожидаемая доходность всех рассматриваемых акций согласно САРМ (Capital Asset Pricing Model - модель оценки финансовых активов) ниже годовой эффективной доходности акций, следовательно, рынок достаточно высоко оценивает акции компаний. То есть данные акции можно покупать и включать их в инвестиционные портфели [9].

Прежде чем перейти к формированию инвестиционного портфеля, рассчитаем коэффициенты корреляции между доходностями акций рассматриваемых компаний (табл. 10), поскольку диверсификация имеет смысл только в том случае, если между доходностями активов низкий коэффициент корреляции.

\footnotetext{
1 Делойт. Обзор рынка черной металлургии. Москва, первое полугодие 2019 г. [Электронный pecypc]. URL: https://www2.deloitte.com/content/dam/Deloitte/ru/Documents/research-center/ metals-1h-2019.pdf.
} 
Анализ доходности и риска акций ПАО “ММК», ПАО “Северсталь» и ПАО «НЛМК» Table 9. Analysis of profitability and risk of MMK, Severstal and NLMK shares

\begin{tabular}{|l|c|c|c|c|c|}
\hline \multicolumn{1}{|c|}{ Показатель } & Формула & МмК & $\begin{array}{c}\text { Север- } \\
\text { сталь }\end{array}$ & НлмК & $\begin{array}{c}\text { Мос } \\
\text { Биржа }\end{array}$ \\
\hline $\begin{array}{l}\text { Ожидаемая } \\
\text { дневная } \\
\text { доходность, \% }\end{array}$ & $E\left(R_{i}\right)=\sum_{k=1}^{N} P_{k} R_{i k}$ & 0,044 & 0,052 & 0,052 & 0,041 \\
\hline $\begin{array}{l}\text { Годовая } \\
\text { эффективная } \\
\text { доходность, } \%\end{array}$ & $\left(1+E\left(R_{i}\right)\right)^{m}-1$ & 11,044 & 13,391 & 13,388 & 10,39 \\
\hline $\begin{array}{l}\text { Стандартное } \\
\text { отклонение, } \\
\text { годовое, \% }\end{array}$ & $\operatorname{var}\left(R_{i}\right) \equiv \sigma_{i}^{2}=E\left[R_{i k}-E\left(R_{i}\right)\right]^{2}$ & 6,56 & 6,70 & 7,26 & 4,67 \\
\hline $\begin{array}{l}\text { Бета, } \beta_{1} \\
\beta_{i}=\frac{\operatorname{cov}\left(R_{i}, R_{m}\right)}{\sigma_{m}^{2}}\end{array}$ & 0,861 & 0,940 & 1,059 & - \\
\hline $\begin{array}{l}\text { Ожидаемая } \\
\text { доходность } \\
\text { согласно САРМ }\end{array}$ & $E\left(R_{i}\right)=r_{f}+\beta_{i}\left[E\left(R_{m}\right)-r_{f}\right]$ & 9,299 & 9,866 & 10,728 & - \\
\hline
\end{tabular}

И с точни к: расчеты авторов, основанные на данных официального сайта Московской биржи.

Таблица 10

\section{Коэффициенты корреляции активов}

Table 10. Correlation coefficient

\begin{tabular}{|c|c|c|c|}
\hline \multirow{2}{*}{ Корреляция } & ММК+Северсталь & НЛМК+Северсталь & ММК+НЛМК \\
\cline { 2 - 4 } & 0,000010 & 0,000011 & 0,000011 \\
\hline
\end{tabular}

И с точни к: расчеты авторов, основанные на данных официального сайта Московской биржи.

Несмотря на то, что компании принадлежат к одной отрасли, коэффициенты корреляции близки к 0, то есть в данном случае возможно сформировать инвестиционный портфель и, таким образом, диверсифицировать часть риска за счет инвестирования в несколько активов ${ }^{1}$. Далее перейдем к формированию инвестиционного портфеля с минимальной дисперсией. Были сформированы три инвестиционных портфеля (табл. 11).

Из представленных данных мы видим, что наименьшее стандартное отклонение у портфеля 1, наибольшая доходность у портфеля 2. Портфель 3 не выгоден, так как имеет при той же ожидаемой доходности высокий уровень рисковости.

Рассмотрим портфель 2: он привлекателен за счет высокой доходности, но имеет высокое стандартное отклонение. Было замечено, что возможно снижение риска данного портфеля путем включения в него 8\% безрискового актива, то есть государственной облигации. Новые пропорции в портфеле представлены в табл. 12 .

Таким образом, ожидаемая доходность снизилась, но осталась выше, чем у портфеля ПАО «ММК» и ПАО «Северсталь», который по результатам предыдущих расчетов казался наилучшим. При этом стандартное отклонение нового портфеля

\footnotetext{
1 Глобальные тенденции, влияющие на развитие металлургической промышленности. Аналитический отчет [Электронный ресурc]. URL: http://kidi.gov.kz/docs/otchety/5531319.pdf.
} 
Расчет портфеля ценных бумаг

Table 11. Portfolio optimization

\begin{tabular}{|c|c|c|c|}
\hline $\begin{array}{l}\text { Расчет портфеля } \\
\text { ценных бумаг }\end{array}$ & $\begin{array}{l}\text { Ожидаемая } \\
\text { доходность }\end{array}$ & $\begin{array}{c}\text { Стандартное } \\
\text { отклонение (год.) }\end{array}$ & Доли в портфеле \\
\hline $\begin{array}{l}\text { 1: ММК, } \\
\text { Северсталь }\end{array}$ & $12,17 \%$ & $4,69 \%$ & $\begin{array}{c}\text { ММК } 51 \%, \\
\text { Северсталь } 49 \%\end{array}$ \\
\hline $\begin{array}{l}\text { 2: НЛМК, } \\
\text { Северсталь }\end{array}$ & $13,39 \%$ & $4,93 \%$ & $\begin{array}{c}\text { НЛМК } 46 \%, \\
\text { Северсталь } 54 \%\end{array}$ \\
\hline 3: ММК, НЛМК & $12,17 \%$ & $4,87 \%$ & $\begin{array}{l}\text { ММК } 55 \%, \\
\text { НЛМК } 45 \%\end{array}$ \\
\hline
\end{tabular}

И с точн и к: расчеты авторов, основанные на данных официального сайта Московской биржи.

Таблица 12

Включение безрискового актива в портфель 2

Table 12. Include risk-free asset in portfolio 2

\begin{tabular}{|l|c|c|c|}
\hline \multicolumn{1}{|c|}{$\begin{array}{c}\text { Расчет портфеля } \\
\text { ценных бумаг }\end{array}$} & $\begin{array}{c}\text { Ожидаемая } \\
\text { доходность }\end{array}$ & $\begin{array}{c}\text { Стандартное } \\
\text { отклонение (год.) }\end{array}$ & Доли в портфеле \\
\hline $\begin{array}{l}\text { НЛМК, } \\
\text { Северсталь, } \\
\text { государственная } \\
\text { облигация* }\end{array}$ & $12,39 \%$ & $4,53 \%$ & $\begin{array}{l}\text { НЛМК } 42 \%, \\
\text { Северсталь } 50 \%, \\
\text { гос. облигация 8\% }\end{array}$ \\
\hline
\end{tabular}

*https://www.rusbonds.ru/ank_obl.asp?tool=135877

Источник: расчеты авторов, основанные на данных официального сайта Московской биржи.

значительно снизилось. Тем самым мы сформировали портфель 2 (ПАО «НЛМК»; ПАО «Северсталь» и государственная облигация) для инвестора, заинтересованного в стратегии минимизации риска портфеля.

\section{Выводы}

Подтверждена гипотеза об эффективности диверсификации отраслевого инвестиционного портфеля на примере компаний металлургической отрасли. Было выявлено, что не всегда соблюдается один из принципов диверсификации, согласно которому максимальное снижение риска достигается за счет включения в портфель ценных бумаг несвязанных между собой отраслей. Создание отраслевого портфеля, то есть включение компаний одних отраслей, может привести к хорошей диверсификации. Мы убедились в том, что создание портфеля позволяет минимизировать риск при высоком уровне дохода. А далее инвесторы формируют предпочтения в зависимости от личной стратегии по отношению к риску.

На основе произведенных расчетов и анализа можно сделать следующие выводы.

Наиболее привлекательной является компания ПАО «Северсталь» и наименее ПАО «НЛМК». С учетом выявленных глобальных стратегических тенденций и для повышения уровня конкурентоспособности на глобальном рыночном пространстве исследуемым «компаниям необходимо разрабатывать серьезные, на грамотной методологической основе, приоритеты. На основе этих приоритетов надо разрабатывать качественные цели. Затем на уровне задач необходимо давать количе- 
ственную оценку. На основе этой оценки надо разрабатывать несколько сценариев, затем делать ресурсный анализ. Тот сценарий, который наиболее работает, надо превращать постепенно в стратегический план, потом в тактические решения, стратегию выхода и так далее» [6].

Ожидаемая доходность акций рассматриваемых компаний согласно модели САРМ ниже годовой эффективной доходности акций, таким образом их следует включать в инвестиционные портфели. Были сформированы отраслевые портфели с минимальной дисперсией для инвестора, придерживающегося стратегии минимизации риска своих вложений. Включение безрискового актива позволило еще больше диверсифицировать часть риска, при этом сохранив значение ожидаемой доходности на приемлемом уровне.

\section{Литература}

1. Боди 3. Принципы инвестиций / З. Боди, А. Кейн, А. Маркус. М. : Вильямс, 2008. 984 с.

2. Буданов И.А., Терентьев Н.Е. Проблемы и направления технологической модернизации металлургического комплекса России в условиях «зеленого» экономического роста // Научные труды: Институт народнохозяйственного прогнозирования РАН. 2017. № 15. C. $76-91$.

3. Буданов И.А., УСтинов В.С. Инновационно-инвестиционные процессы развития металлургического производства в России // Научные труды: Институт народнохозяйственного прогнозирования РАН. 2015. № 13. С. 324-347.

4. Глазунов В.Г. Анализ финансового состояния предприятия // Финансы. 2005. № 2. C. $55-57$.

5. Гончаров А.И. Восстановление платежеспособности предприятия: Модель обновления основных средств // Финансы. 2004. № 9. С. 65-66.

6. Ермаков А.Н. Диверсификация структуры портфеля акций инвестиционной компании // Научные исследования. Серия: Общественные науки. 2009. № 3. С. 39-42.

7. Квинт В.Л. Глобальный формирующийся рынок - влияние на стратегию России и стратегическое развитие российских компаний // Эффективное антикризисное управление. 2012. № 3. C. 50-61.

8. Квинт В. Л. Концепция стратегирования. Т. І. СПб. : СЗИУ РАНХиГС, 2019. 132 с.

9. Клитина Н.А. Оптимизация портфеля ценных бумаг в зависимости от диверсификации инвестиций // Финансовые исследования. 2010. № 1 (26). С. 41-51.

10. Клитина Н.А. Формирование портфелей ценных бумаг для различных типов инвесторов // Финансовая аналитика: проблемы и решения. 2011. № 23. С. 9-14.

11. Подшивалова В. С. Показатели EBIT и EBITDA: особенности вычисления по данным МСФО отчетности // Современные тенденции в экономике и управлении. 2016. № 41-1. С. 174179.

12. Семин А. Опережающее развитие производства высококачественной стали - государственный приоритет в области металлургии // Металлы Евразии. 2017. № 4. С. 14-15.

13. Fabozzi F., Grant J. (2001). Modern Portfolio Theory, Capital Market Theory, and Asset Pricing Models. URL: https://www.researchgate.net/publication/272157556_Modern_Portfolio_Theory_ Capital_Market_Theory_and_Asset_Pricing_Models.

14. Kvint V. L. Strategy for the Global Market: Theory and practical applications. Routledge, New York, 2016. 520 p.

15. Markowitz H. M. (March 1952). Portfolio Selection // The Journal of Finance. URL: https://www. math.ust.hk/ maykwok/courses/ma362/07F/markowitz_JF.pdf.

\section{Об авторах}

Гаврилина Дарья Николаевна, преподаватель кафедры экономической и финансовой стратегии Московской школы экономики Московского государственного университета им. М.В. Ломоносова (Москва, Российская Федерация); dariagavrilina23@gmail.com

Огарева Анна Сергеевна, студент Московской школы экономики Московского государственного университета им. М.В. Ломоносова (Москва, Российская Федерация); ogareva-a@ mail.ru 


\section{References}

1. Body Z. Investment Principles / Z. Body, A. Kane, A. Marcus. M.: Williams, 2008. 984 p. (In rus).

2. Budanov I. A., Terentyev N. E. Issues and directions of Russia's metallurgy sector technological modernization within green growth context // Proceedings: Institute of Economic Forecasting, Russian Academy of Sciences [Nauchnye trudy: Institut narodnokhozyaistvennogo prognozirovaniya RAN]. 2017. N 15. P. 76-91. (In rus).

3. Budanov I. A., Ustinov V. S. (2015). Innovation and investment processes of metallurgy development in Russia // Proceedings: Institute of Economic Forecasting, Russian Academy of Sciences [Nauchnye trudy: Institut narodnokhozyaistvennogo prognozirovaniya RAN]. 2015. N 13. P. 324347. (In rus).

4. Glazunov V. G. Analysis of the financial condition of the enterprise // Finance [Finansy]. 2005. No. 2. P. 55-57. (In rus).

5. Goncharov A. I. Restoring the solvency of an enterprise: a model for updating fixed assets // Finance [Finansy]. 2004. N 9. P. 65-66. (In rus).

6. Ermakov A. N. Diversification of the structure of the stock portfolio of an investment company // Scientific Research. Series: Social Sciences [Nauchnye issledovaniya. Seriya: Obshchestvennye nauki]. 2009. N 3. P. 39-42. (In rus).

7. Kvint V. L. The global emerging market - the impact on the strategy of Russia and the Russian companies strategic development // Effective crisis management [Effektivnoe antikrizisnoe upravlenie]. 2012. N 3. P. 50-61. (In rus).

8. Kvint V. L. The concept of strategizing. Vol. I. St. Petersburg : NWIM of RANEPA, 2019. 132 p. (In rus).

9. Klitina N.A. Optimization of the securities portfolio depending on the diversification of investments // Financial studies [Finansovye issledovaniya]. 2010. N 1 (26). P. 41-51. (In rus).

10. Klitina N.A. The formation of securities portfolios for various types of investors // Financial analytics: problems and solutions [Finansovaya analitika: problemy i resheniya]. 2011. N 23. P. 9-14. (In rus).

11. Podshivalova V.S. Indicators of EBIT and EBITDA: features of calculation according to IFRS financial statements // Modern trends in economics and management [Sovremennye tendentsii v ekonomike i upravlenii]. 2016. N 41-1. P. 174-179. (In rus).

12. Semin A. The accelerated development of high-quality steel production is a state priority in the field of metallurgy // Metals of Eurasia [Metally Evrazii.]. 2017. N 4. P. 14-15. (In rus).

13. Fabozzi F., Grant J. (2001). Modern Portfolio Theory, Capital Market Theory, and Asset Pricing Models. URL: https://www.researchgate.net/publication/272157556_Modern_Portfolio_Theory_ Capital_Market_Theory_and_Asset_Pricing_Models.

14. Kvint V. L. Strategy for the Global Market: Theory and practical applications. Routledge, New York, 2016. 520 p.

15. Markowitz H. M. (March 1952). Portfolio Selection // The Journal of Finance. URL: https://www. math.ust.hk/ maykwok/courses/ma362/07F/markowitz_JF.pdf.

\section{About the authors:}

Daria N. Gavrilina, Lecturer of Economic and Financial Strategy Department at Moscow School of Economics, Lomonosov Moscow State University (Moscow, Russian Federation); dariagavrilina23@gmail.com

Anna S. Ogareva, Student of Moscow School of Economics, Lomonosov Moscow State University (Moscow, Russian Federation); ogareva-a@mail.ru 